\title{
Article \\ Crystal Evolution of Calcium Silicate Minerals Synthesized by Calcium Silicon Slag and Silica Fume with Increase of Hydrothermal Synthesis Temperature
}

\author{
Zhijie Yang ${ }^{1,2, *(\mathbb{D}}$, De Zhang ${ }^{1,2}$, Yang Jiao ${ }^{1,2}$, Chengyang Fang ${ }^{1,2}$, Dong Kang ${ }^{1,2}$, Changwang Yan ${ }^{1,2}$ \\ and Ju Zhang ${ }^{1,2}$
}

check for updates

Citation: Yang, Z.; Zhang, D.; Jiao, Y.; Fang, C.; Kang, D.; Yan, C.; Zhang, J. Crystal Evolution of Calcium Silicate Minerals Synthesized by Calcium Silicon Slag and Silica Fume with Increase of Hydrothermal Synthesis Temperature. Materials 2022, 15, 1620. https://doi.org/10.3390/ma15041620

Academic Editors: Miguel Angel Sanjuán and F. Pacheco-Torgal

Received: 7 December 2021

Accepted: 17 February 2022

Published: 21 February 2022

Publisher's Note: MDPI stays neutral with regard to jurisdictional claims in published maps and institutional affiliations.

Copyright: (C) 2022 by the authors. Licensee MDPI, Basel, Switzerland. This article is an open access article distributed under the terms and conditions of the Creative Commons Attribution (CC BY) license (https:// creativecommons.org/licenses/by/ $4.0 /)$.
1 School of Mining and Technology, Inner Mongolia University of Technology, Hohhot 010051, China; 20201100458@imut.edu.cn (D.Z.); 20211800659@imut.edu.cn (Y.J.); 20211100472@imut.edu.cn (C.F.); 20201100459@imut.edu.cn (D.K.); yanchangwang@imut.edu.cn (C.Y.); zj970741@imut.edu.cn (J.Z.)

2 The Key Laboratory of Green Development for Mineral Resources, Inner Mongolia University of Technology, Hohhot 010051, China

* Correspondence: yangzj@imut.edu.cn

\begin{abstract}
In order to realize high-value utilization of calcium silicon slag (CSS) and silica fume (SF), the dynamic hydrothermal synthesis experiments of CSS and SF were carried out under different hydrothermal synthesis temperatures. In addition, phase category, microstructure, and micropore parameters of the synthesis product were analyzed through testing methods of XRD, SEM, EDS and micropore analysis. The results show that the main mechanism of synthesis reaction is that firstly $\beta$-Dicalcium silicate, the main mineral in CSS, hydrates to produce amorphous $\mathrm{C}-\mathrm{S}-\mathrm{H}$ and $\mathrm{Ca}(\mathrm{OH})_{2}$, and the environment of system is induced to strong alkaline. Therefore, the highly polymerized Si-O bond of SF is broken under the polarization of $\mathrm{OH}^{-}$to form $\left(\mathrm{SiO}_{4}\right)$ of $\mathrm{Q}^{0}$. Next, amorphous $\mathrm{C}-\mathrm{S}-\mathrm{H}$, $\mathrm{Ca}(\mathrm{OH})_{2}$ and $\left(\mathrm{SiO}_{4}\right)$ of $\mathrm{Q}^{0}$ react each other to gradually produce various of calcium silicate minerals. With an increase of synthesis temperature, the crystal evolution order for calcium silicate minerals is cocoon-like C-S-H, mesh-like C-S-H, large flake-like gyrolite, small flake-like gyrolite, petal-like gyrolite, square flake-like calcium silicate hydroxide hydrate, and strip-like tobermorite. In addition, petal-like calcium silicate with high average pore volume (APV), specific surface area (SSA) and low average pore diameter (APD) can be prepared under the $230{ }^{\circ} \mathrm{C}$ synthesis condition.
\end{abstract}

Keywords: calcium silicon slag; silica fume; hydrothermal synthesis temperature; calcium silicate minerals; crystal evolution

\section{Introduction}

Calcium silicate hydrate minerals based on $\mathrm{CaO}-\mathrm{SiO}_{2}-\mathrm{H}_{2} \mathrm{O}$ system can be prepared using different calcium raw materials and silicate raw materials under different hydrothermal synthesis conditions. These crystal calcium silicate minerals take on different microstructure such as agglomerate-like [1], honeycomb-like [2], rod-like [3], fibrous-like [4], cocoonlike [5], needle-like [6] and so on. At the same time, these different crystal of calcium silicate minerals can be used in papermaking [7], rubber [8], building materials [9,10], sewage treatment and air purification [11-14], thermal insulation material [15] and other fields. The CSS is as a new type of waste discharged from aluminum extraction technology using fly ash [16], and its main chemical components are $\mathrm{CaO}$ and $\mathrm{SiO}_{2}$. Therefore, the authors carried out preparation of different calcium silicate minerals using CSS and SF as the main raw materials through the dynamic hydrothermal synthesis process [17]. It not only solved the problem of CSS treatment that restricts the development of aluminum extraction from fly ash, but also realized the high-value utilization of CSS. However, in the process of promoting industrial application of the synthesized calcium silicate minerals, it is found that the quality of different crystal calcium silicate minerals fluctuates greatly, which is 
difficult to meet the requirements of the downstream industry. The main reason is that the hydrothermal synthesis mechanism of calcium silicate minerals synthesized by CSS and SF is not clear. Furthermore, it is found that synthesis temperature is one of key factors affecting the crystal of calcium silicate minerals. Wei Guan synthesized porous calcium silicate mineral with highly active $\mathrm{SiO}_{2}$ at $110{ }^{\circ} \mathrm{C}$ through hydrothermal synthesis [18]. Ezgi Ogur synthesized xonotlite as the main phase using waste glass and lime, when synthesis temperature was at $220^{\circ} \mathrm{C}$ and C/S molar ratio was 0.83 [19], but there is little study on how the synthesis temperature affects crystal of calcium silicate minerals synthesized by CSS and SF.

Therefore, in order to clarify crystal control theory of calcium silicate minerals, in the paper, the hydrothermal synthesis experiments of calcium silicate minerals using CSS and SF were conducted under different synthesis temperature. In addition, the hydrothermal synthesis reaction mechanism of CSS and SF was discussed to clarify the effect of synthesis temperature on the formation and evolution of calcium silicate minerals with different crystal.

\section{Materials and Methods}

\subsection{Materials}

The CSS, SF and distilled water are used as main raw materials in experiment. The CSS was supplied by Datang Renewable Resources company, which built first production line of extracting aluminum from fly ash in the world. The SF was supplied by Inner Mongolia Erdos Ferrosilicon alloy company. The chemical and phase composition of CCS and SF are shown in Table 1 and Figure 1. The main phases of CSS are $\beta$-dicalcium silicate and calcite. The main phase of SF is glass phase.

Table 1. Content of chemical composition for raw materials (calculated by mass fraction \%).

\begin{tabular}{cccccccccccc}
\hline Chemical Composition & $\mathrm{SiO}_{\mathbf{2}}$ & $\mathrm{Fe}_{\mathbf{2}} \mathbf{O}_{\mathbf{3}}$ & $\mathrm{Al}_{\mathbf{2}} \mathbf{O}_{\mathbf{3}}$ & $\mathbf{C a O}$ & $\mathbf{M g O}$ & $\mathrm{Na}_{\mathbf{2}} \mathbf{O}$ & $\mathbf{K}_{\mathbf{2}} \mathbf{O}$ & $\mathbf{S O}_{3}$ & $\mathbf{P}_{\mathbf{2}} \mathbf{O}_{\mathbf{5}}$ & $\mathbf{F}$ & $\mathrm{Cl}$ \\
\hline $\mathrm{CSS}$ & 29.26 & 2.53 & 5.30 & 55.50 & 3.61 & 2.58 & 0.36 & 0.73 & 0.14 & - & 0.42 \\
$\mathrm{SF}$ & 72.15 & 1.16 & 0.59 & 7.50 & 7.43 & 0.68 & 4.20 & 3.17 & 0.56 & 1.74 & 0.82 \\
\hline
\end{tabular}

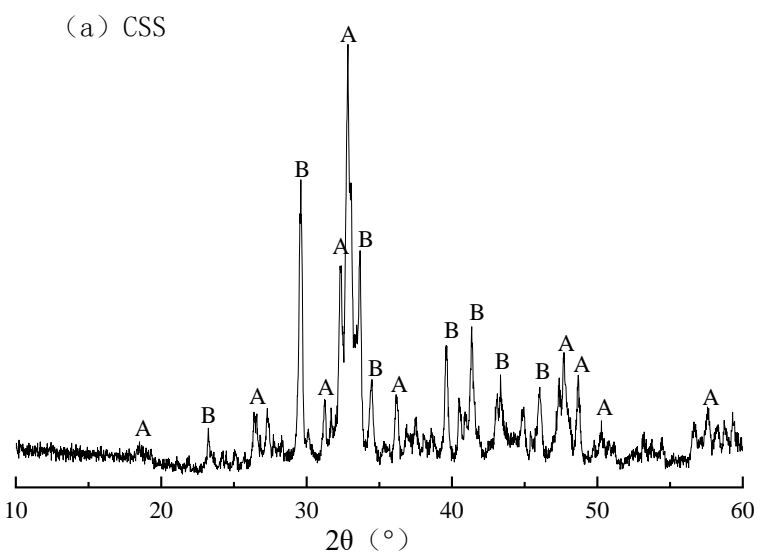

(b) SF

Figure 1. XRD patterns of CSS and SF; (a)- $\beta$-dicalcium silicate $\left(\beta-2 \mathrm{CaO} \cdot \mathrm{SiO}_{2}\right)(\mathbf{b})$-calcite $\left(\mathrm{CaCO}_{3}\right)$.

\subsection{Methods}

The CSS was dried in blast drying oven at $110^{\circ} \mathrm{C}$ for about $5 \mathrm{~h}$, and then CSS dried was milled to particle size less than $45 \mu \mathrm{m}$ in a ball mill again. According to the $100 \mathrm{~g} \mathrm{CSS}$ and $58.23 \mathrm{~g}$ SF were weighed and $2373.45 \mathrm{~g}$ distilled water was added to make C/S molar ratio of 0.9 and liquid-solid ratio of 15:1 for each synthesis experiment. After mixing, the mixture was put into a $5 \mathrm{~L}$ high-pressure reactor. The dynamic hydrothermal synthesis experiments were conducted according to process parameters of the stirring rate $300 \mathrm{r} / \mathrm{min}$ and the heating rate $8^{\circ} \mathrm{C} / \mathrm{min}$ to corresponding synthesis temperature and constant temperature 
for $6 \mathrm{~h}$. Then when high-pressure reactor was gradually cooled to about $20^{\circ} \mathrm{C}$, the synthetic material was removed from the high-pressure reactor and dehydrated through a filter and dried in a blast drying oven at $110^{\circ} \mathrm{C}$ for $5 \mathrm{~h}$.

Hydrothermal synthesis temperature from $180{ }^{\circ} \mathrm{C}$ to $260^{\circ} \mathrm{C}$, one synthesis experiment was executed for every $10^{\circ} \mathrm{C}$, a total of 9 experiments. Finally, XRD (PANalytical, Almelo, The Netherlands, $X^{\prime}$ Pert Powder 3, Cu target, $40 \mathrm{kV}$, step 0.02 ${ }^{\circ}$ ), SEM (S-4800, Hitachi, Tokyo, Japan) and micropore analyzer (V-Sorrb 2800TP, Gold APP Instruments Corporation, Beijing, China) were used to analyze the phase category, micromorphology, micropore parameters of synthesis product.

\section{Results and Discussion}

\subsection{Phase Evolution of Calcium Silicate Minerals with Increase of Hydrothermal Synthesis Temperature}

$\mathrm{XRD}$ analysis result of synthesis products at different synthesis temperatures is shown in Figure 2, and mineral phase information of synthesis calcium silicate is also shown in Table 2 . When the synthesis temperature is between $180^{\circ} \mathrm{C}$ and $200^{\circ} \mathrm{C}$, the main phases in the synthesis products are $\beta$-dicalcium silicate, calcite, and crystalline $\mathrm{C}-\mathrm{S}-\mathrm{H}$. That because the $\beta$ dicalcium silicate, main phase in the CSS, occurs hydration reaction according to Equation (1) under dynamic hydrothermal synthesis conditions. Furthermore, amorphous $\mathrm{C}-\mathrm{S}-\mathrm{H}$ and $\mathrm{Ca}(\mathrm{OH})_{2}$ are generated at first. Then under high temperature and high pressure, amorphous $\mathrm{C}-\mathrm{S}-\mathrm{H}$ is further crystallized to form crystalline C-S-H. Meanwhile, the environment of system is induced to strong alkaline. Therefore, the highly polymerized Si-O bond of SF are broken under the polarization of $\mathrm{OH}^{-}$to form $\left(\mathrm{SiO}_{4}\right)$ of $\mathrm{Q}^{0}$ [20], and reacts with $\mathrm{Ca}(\mathrm{OH})_{2}$ to form crystalline $\mathrm{C}-\mathrm{S}-\mathrm{H}$, and this mechanism was also confirmed by Rachel Camerini in studying the synthesis kinetics of calcium silicate hydrate [21]. However, because $\beta$ dicalcium silicate is a slower hydration rate mineral and its hydration degree is less than $10.3 \%$ in 28 days [22], $\beta$-dicalcium silicate in CSS cannot be completely hydrated and will be partially remained. At the same time, because calcite almost does not hydrolyze or react with SF under condition of high temperature and pressure, the calcite phase contained in synthesis products may be derived from the original calcite in the CSS.

$$
2 \mathrm{CaO} \cdot \mathrm{SiO}_{2}+m \mathrm{H}_{2} \mathrm{O}=x \mathrm{CaO} \cdot \mathrm{SiO}_{2} \cdot(m+x-2) \mathrm{H}_{2} \mathrm{O}+(2-x) \mathrm{Ca}(\mathrm{OH})_{2}
$$

Since $\beta$-dicalcium silicate hydration will be intensified with temperature increase. Therefore, when the synthesis temperature increases to $210-230{ }^{\circ} \mathrm{C}$, the more $\mathrm{Ca}(\mathrm{OH})_{2}$ is generated. Therefore, the reaction between $\mathrm{Ca}(\mathrm{OH})_{2}$ with $\mathrm{SF}$ is intensified, and generating gyrolite $\left(\mathrm{Ca}_{4}\left(\mathrm{Si}_{6} \mathrm{O}_{15}\right)(\mathrm{OH})_{2} \cdot 3 \mathrm{H}_{2} \mathrm{O}\right)$ phase with higher $\mathrm{C} / \mathrm{S}$ molar ratio. When the synthesis temperature increased to $240{ }^{\circ} \mathrm{C}$, not only Calcium silicate hydroxide hydrate $\left(\mathrm{Ca}_{4.5} \mathrm{Si}_{6} \mathrm{O}_{15}(\mathrm{OH})_{2} \cdot 3 \mathrm{H}_{2} \mathrm{O}\right)$ and tobermorite $\left(5 \mathrm{CaO} \cdot 6 \mathrm{SiO}_{2} \cdot 5 \mathrm{H}_{2} \mathrm{O}\right)$ appear in the synthesis products, but also the phases of $\beta$-dicalcium silicate and crystalline $\mathrm{C}-\mathrm{S}-\mathrm{H}$ disappears. This indicates that under synthesis temperature of $240^{\circ} \mathrm{C}$ and synthesis time of $6 \mathrm{~h}$, $\beta$-dicalcium silicate has been completely hydrated, and a large number of $\mathrm{Ca}(\mathrm{OH})_{2}$ reacted with $\mathrm{SF}$ to generate calcium silicate minerals with higher $\mathrm{C} / \mathrm{S}$ molar ratio. This is basically similar to the experimental results of synthesis tobermorite with fly ash and quartz or lime [23,24].

Table 2. Minerals phase information of hydrothermal synthesis of hydrated calcium silicate.

\begin{tabular}{|c|c|c|c|c|}
\hline No. & Phase & Chemical Formula & PDF Card No. & Main $2 \theta\left({ }^{\circ}\right)$ \\
\hline A & $\beta$-dicalcium silicate & $\beta-2 \mathrm{CaO} \cdot \mathrm{SiO}_{2}$ & 01-083-0460 & $23.190,32.169,41.174$ \\
\hline $\mathrm{B}$ & calcite & $\mathrm{CaCO}_{3}$ & 01-072-1937 & $29.369,39.370,48.452$ \\
\hline $\mathrm{C}$ & crystalline $\mathrm{C}-\mathrm{S}-\mathrm{H}$ & $\mathrm{C}-\mathrm{S}-\mathrm{H}$ & $00-002-0068$ & $30.168,31.589,37.281$ \\
\hline $\mathrm{D}$ & gyrolite & $\mathrm{Ca}_{4}\left(\mathrm{Si}_{6} \mathrm{O}_{15}\right)(\mathrm{OH})_{2} \cdot 3 \mathrm{H}_{2} \mathrm{O}$ & $00-042-1425$ & $21.065,28.227,31.797$ \\
\hline $\mathrm{E}$ & tobermorite & $5 \mathrm{CaO} \cdot 6 \mathrm{SiO}_{2} \cdot 5 \mathrm{H}_{2} \mathrm{O}$ & $00-045-1480$ & $16.251,30.044,31.867$ \\
\hline $\mathrm{F}$ & calcium silicate hydroxide hydrate & $\mathrm{Ca}_{4 .} \mathrm{Si}_{6} \mathrm{O}_{15}(\mathrm{OH})_{2} \cdot 3 \mathrm{H}_{2} \mathrm{O}$ & $00-043-1488$ & $35.817,36.782,45.291$ \\
\hline
\end{tabular}




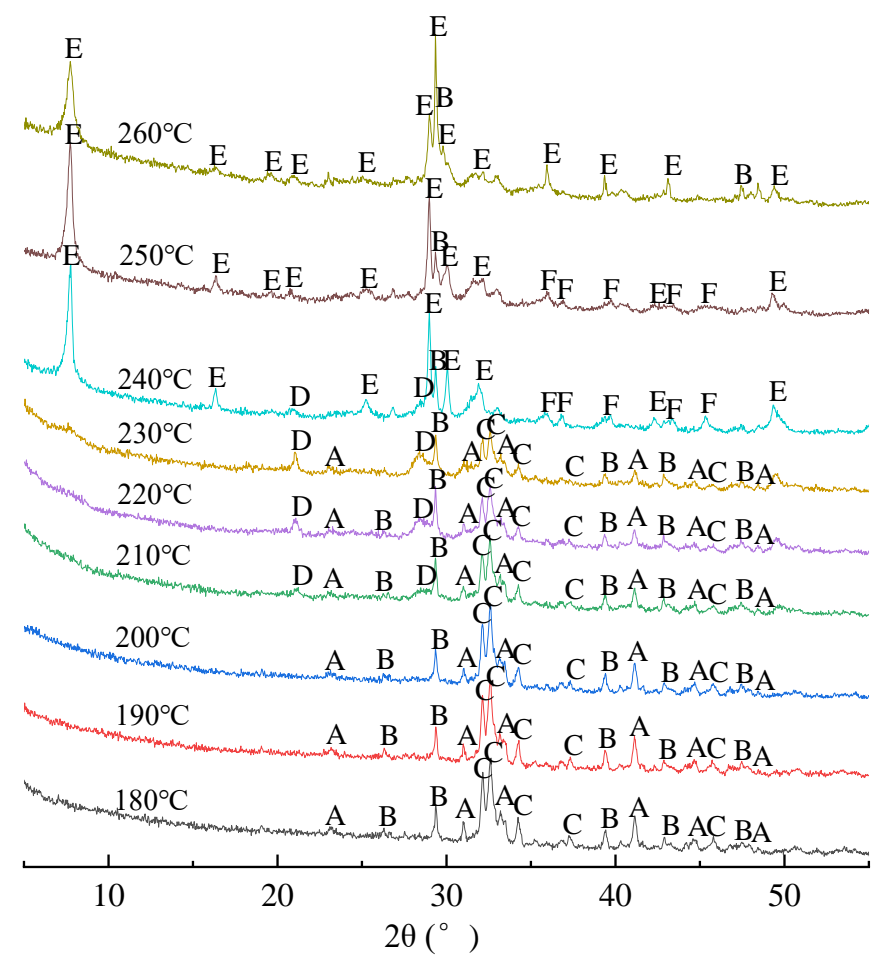

Figure 2. $\mathrm{XRD}$ patterns of synthesis products. $\mathrm{A}$-dicalcium silicate $\left(\beta-2 \mathrm{CaO} \cdot \mathrm{SiO}_{2}\right), \mathrm{B}-$ calcite $\left(\mathrm{CaCO}_{3}\right)$, C-crystalline C-S-H, D-gyrolite $\left(\mathrm{Ca}_{4}\left(\mathrm{Si}_{6} \mathrm{O}_{15}\right)(\mathrm{OH})_{2} \cdot 3 \mathrm{H}_{2} \mathrm{O}\right)$, E-tobermorite $\left(5 \mathrm{CaO} \cdot 6 \mathrm{SiO}_{2} \cdot 5 \mathrm{H}_{2} \mathrm{O}\right)$, $\mathrm{F}$-calcium silicate hydroxide hydrate $\left(\mathrm{Ca}_{4.5} \mathrm{Si}_{6} \mathrm{O}_{15}(\mathrm{OH})_{2} \cdot 3 \mathrm{H}_{2} \mathrm{O}\right)$.

When the synthesis temperature continues to rise to $250{ }^{\circ} \mathrm{C}$, there are only tobermorite, calcium silicate hydroxide hydrate and calcite phase in the synthesis products, while the gyrolite phase disappears. When the synthesis temperature reaches $260{ }^{\circ} \mathrm{C}$, calcium silicate hydroxide hydrate phase also disappears, only tobermorite and calcite phase are remained. This shows that, with increase of synthesis temperature, the hydrothermal synthesis reaction of CSS and SF will generate calcium silicate mineral with higher and higher C/S molar ratio.

Based on the above analysis, the main synthesis reaction mechanism is that firstly $\beta$-dicalcium silicate, the main mineral in CSS, hydrates to produce amorphous C-S-H and $\mathrm{Ca}(\mathrm{OH})_{2}$, and inducing strong alkaline environment in system. Therefore, the highly polymerized $\mathrm{Si}-\mathrm{O}$ bond of $\mathrm{SF}$ are broken under the polarization of $\mathrm{OH}^{-}$to form $\left(\mathrm{SiO}_{4}\right)$ of $\mathrm{Q}^{0}$. Then at condition of high temperature and high press, amorphous $\mathrm{C}-\mathrm{S}-\mathrm{H}, \mathrm{Ca}(\mathrm{OH})_{2}$ and $\left(\mathrm{SiO}_{4}\right)$ of $\mathrm{Q}^{0}$ react each other to gradually produce various of calcium silicate minerals with higher and higher C/S molar ratio with increase of synthesis temperature.

\subsection{Micromorphology Evolution of Calcium Silicate Minerals with Increase of Hydrothermal Synthesis Temperature}

SEM images of 50,000 times and 10,000 times are shown as follows in Figure 3.
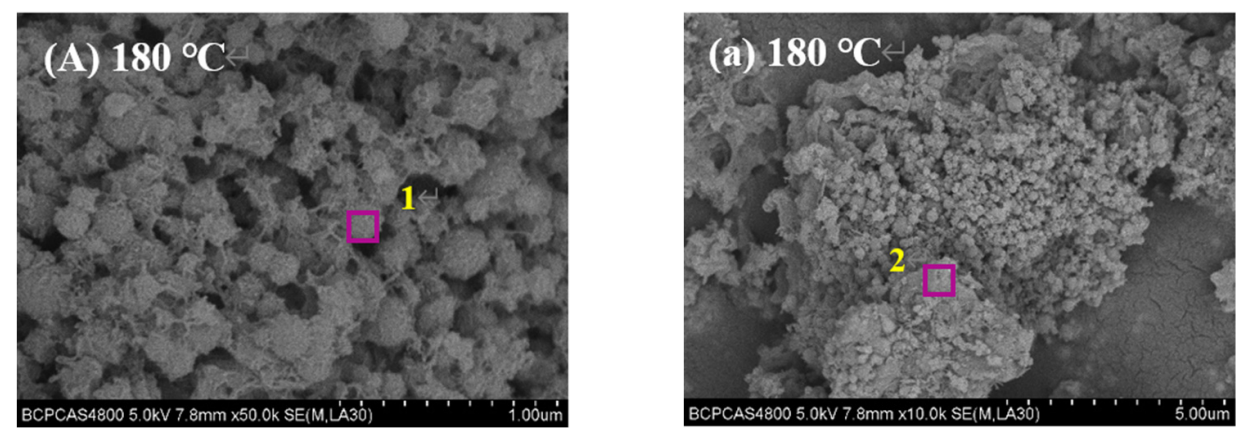

Figure 3. Cont. 

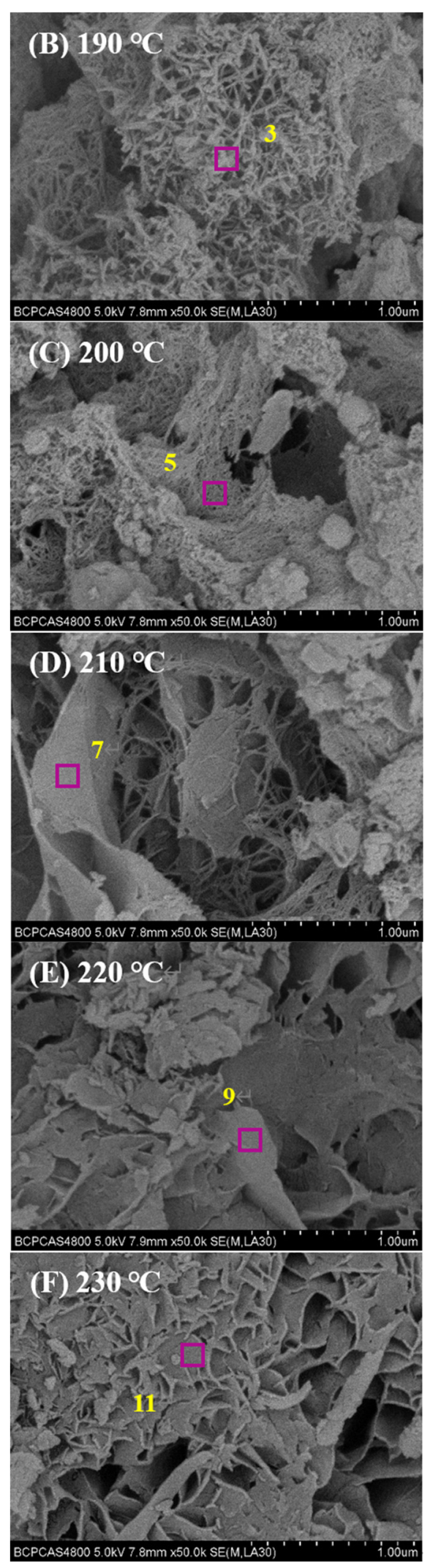

Figure 3. Cont.
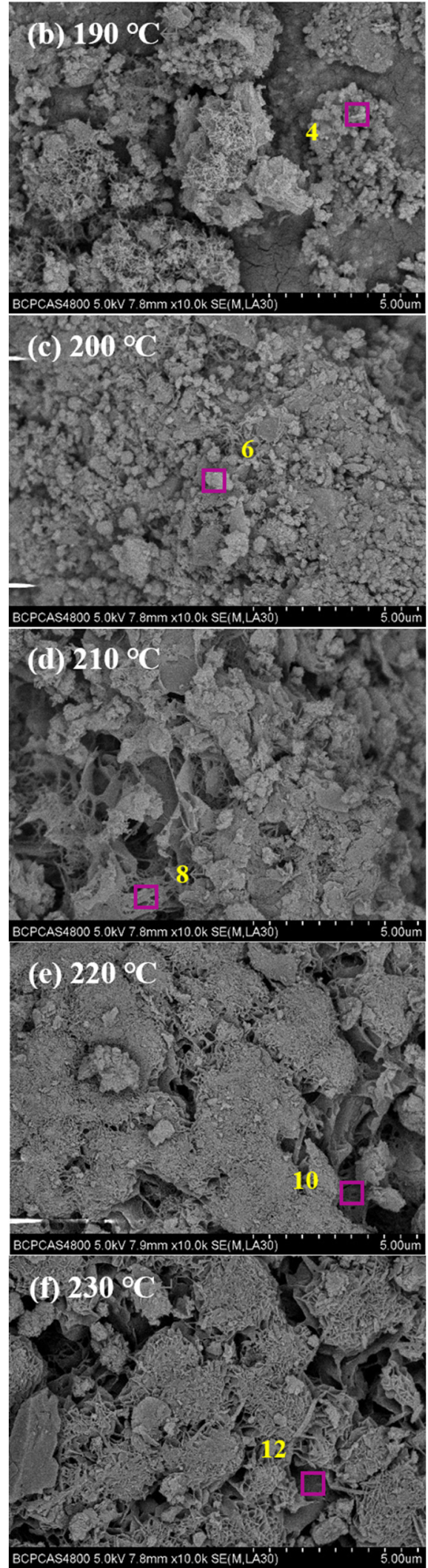

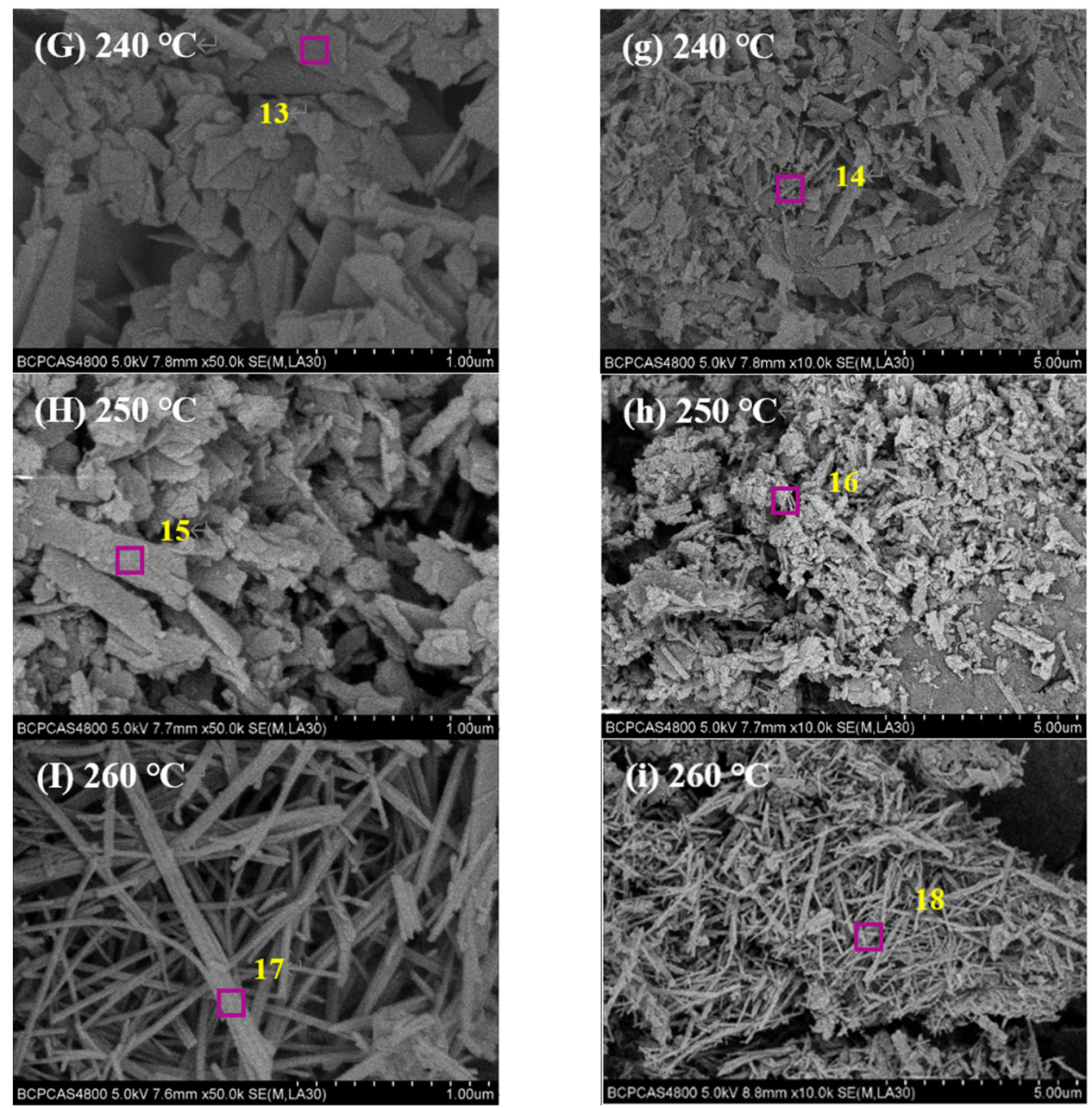

Figure 3. SEM images of synthesis products under different hydrothermal synthesis temperature; the uppercase letters represent SEM images of 50,000 times while the lowercase letters represent SEM images of 10,000 times.

In addition, atom molar ratio of special regions was tested by EDS to infer the phase of calcium silicate minerals with different micromorphology, and the final results are shown in Table 3.

Figure 3 shows that the micromorphology of main synthesis products is cocoon-like sphere at temperatures of $180{ }^{\circ} \mathrm{C}$, as shown in Figure 3A. The average particle size of cocoon-like sphere crystal is about $1.5 \mathrm{~mm}$, and the EDS analysis result is shown in region 1 in Table 3. However, in addition to cocoon-like crystalline C-S-H, there are other block-like minerals. EDS analysis results indicate block-like minerals are calcite as shown region 2 of Table 3. The atom molar ratio of cocoon-like phase is similar to crystalline $\mathrm{C}-\mathrm{S}-\mathrm{H}$, which can be inferred as crystalline $\mathrm{C}-\mathrm{S}-\mathrm{H}$ phase. When the synthesis temperature increases to $190{ }^{\circ} \mathrm{C}$ and $200^{\circ} \mathrm{C}$, the micromorphology of synthesis product takes on mesh-like, as shown in Figure $3 \mathrm{~B}, \mathrm{C}$. The EDS analysis result are shown in region 3 and region 5 of Table 3 . The atom molar ratio of mesh-like phase is also similar to crystalline $\mathrm{C}-\mathrm{S}-\mathrm{H}$, which can be inferred as crystalline $\mathrm{C}-\mathrm{S}-\mathrm{H}$ phase. However, there are a large number of granular-like minerals in Figure $3 b$, and the EDS results show the granular-like minerals are $\beta$-dicalcium silicate as shown in region 4 of Table 3 . Furthermore, the block-like minerals are verified as calicate as as shown in region 6 of Table 3. Therefore, although the main phase of synthesis products is crystalline C-S-H at temperature $180{ }^{\circ} \mathrm{C}, 190^{\circ} \mathrm{C}$ and $200^{\circ} \mathrm{C}$, their crystal is different. Therefore, combining with the XRD analysis results, it can be inferred that the amorphous $\mathrm{C}-\mathrm{S}-\mathrm{H}$ is firstly generated in the process of the dynamic hydrothermal synthesis, and it continues to develop and grow with the increase of synthesis temperature, and its crystal 
micromorphology evolves from cocoon-like to mesh-like. At the same time, there are also incomplete hydration $\beta$-dicalcium silicate and calcite generated by carbonization, which is also consistent with the XRD analysis above.

Table 3. EDS analysis results for different microcosmic region.

\begin{tabular}{|c|c|c|c|c|c|c|c|c|c|c|}
\hline \multirow{2}{*}{$\begin{array}{l}\text { Microcosmic } \\
\text { Region }\end{array}$} & \multirow{2}{*}{ Micromorphology } & \multicolumn{7}{|c|}{ Atom Molar Ratio (\%) } & \multirow[b]{2}{*}{$\mathrm{C}$} & \multirow{2}{*}{$\begin{array}{c}\text { Corresponding } \\
\text { Phase }\end{array}$} \\
\hline & & $\mathrm{O}$ & Al & Si & $\mathrm{Ca}$ & $\mathrm{Na}$ & Mg & $\mathrm{Fe}$ & & \\
\hline 1 & cocoon-like & 63.54 & 0.52 & 17.15 & 16.42 & 0.24 & 0.81 & 1.32 & - & crystalline C-S-H \\
\hline 2 & block-like & 58.72 & 0.21 & 0.10 & 20.04 & - & 0.10 & 0.10 & 20.73 & calcite \\
\hline 3 & mesh-like & 63.36 & 0.52 & 17.22 & 16.72 & 0.35 & 0.81 & 1.02 & - & crystalline $\mathrm{C}-\mathrm{S}-\mathrm{H}$ \\
\hline 4 & granular-like & 54.42 & 1.75 & 14.76 & 27.02 & 0.56 & 1.13 & 0.36 & - & $\beta$-dicalcium silicate \\
\hline 5 & mesh-like & 65.72 & 0.33 & 16.95 & 16.23 & 0.12 & 0.44 & 0.21 & - & crystalline $\mathrm{C}-\mathrm{S}-\mathrm{H}$ \\
\hline 6 & block-like & 57.72 & 0.53 & 0.21 & 20.46 & - & 0.21 & 0.24 & 20.63 & calcite \\
\hline 7 & large flake-like & 67.32 & 0.15 & 19.25 & 12.42 & 0.21 & 0.52 & 0.13 & - & gyrolite \\
\hline 8 & mesh-like & 66.52 & 0.33 & 16.15 & 16.23 & 0.12 & 0.44 & 0.21 & - & crystalline C-S-H \\
\hline 9 & small flake-like & 64.25 & 0.44 & 19.05 & 12.34 & 0.13 & 2.23 & 1.56 & - & gyrolite \\
\hline 10 & mesh-like & 65.72 & 0.33 & 16.95 & 16.23 & 0.12 & 0.44 & 0.21 & - & crystalline C-S-H \\
\hline 11 & petal-like & 67.44 & 0.12 & 20.35 & 11.03 & 0.65 & 0.36 & 0.05 & - & gyrolite \\
\hline 12 & small flake-like & 64.15 & 0.44 & 18.45 & 12.64 & 0.23 & 2.23 & 1.56 & - & gyrolite \\
\hline 13 & square flake-like & 64.07 & 0.05 & 20.67 & 13.41 & 0.34 & 1.27 & 0.19 & - & $\begin{array}{c}\text { calcium silicate } \\
\text { hydroxide hydrate }\end{array}$ \\
\hline 14 & strip-like & 66.22 & 0.33 & 17.45 & 15.23 & 0.12 & 0.44 & 0.21 & - & tobermorite \\
\hline 15 & square flake-like & 65.27 & 0.19 & 19.47 & 13.09 & 0.27 & 1.66 & 0.05 & - & $\begin{array}{c}\text { calcium silicate } \\
\text { hydroxide hydrate }\end{array}$ \\
\hline 16 & strip-like & 64.67 & 0.36 & 18.35 & 15.42 & 0.45 & 0.52 & 0.23 & - & tobermorite \\
\hline 17 & strip-like & 65.34 & 0.34 & 17.28 & 15.37 & 0.26 & 0.41 & 1.00 & - & tobermorite \\
\hline 18 & strip-like & 66.23 & 0.26 & 17.91 & 14.83 & 0.14 & 0.32 & 0.31 & - & tobermorite \\
\hline
\end{tabular}

When the synthesis temperature rises to $210{ }^{\circ} \mathrm{C}$, it is found in Figure $3 \mathrm{D}, \mathrm{d}$ that large flake-like phase grows into the mesh-like phase. The EDS analysis results are shown in region 7 of Table 3 . The atom molar ratio of these large flake-like phase is similar to the gyrolite, which can be inferred as the gyrolite phase [25]. In addition, mesh-like minerals are still crystalline $\mathrm{C}-\mathrm{S}-\mathrm{H}$ as shown in region 8 of Table 3 . When the synthesis temperature rises to $220{ }^{\circ} \mathrm{C}$, the micromorphology of synthesis products is also flake-like, but these flake-like phases intertwine each other, as shown in Figure 3E. Compared with the flake-like phase generated at $210^{\circ} \mathrm{C}$, the grain size is smaller. The EDS analysis result is shown in region 9 of Table 3 . The atom molar ratio of small flake-like phase is similar to the gyrolite, so small flake-like phase is the gyrolite. However, the Figure 3e shows that there is still incompletely transformed crystalline C-S-H at hydrothermal synthesis of $220^{\circ} \mathrm{C}$, as shown in region 10 of Table 3 . When the synthesis temperature continues to rise to $230{ }^{\circ} \mathrm{C}$, it is observed in Figure 3F that the micromorphology of the synthesis product is petal-like, and the connection of each flake-like grain is closer, and the grain size is smaller. EDS analysis results are shown in region 11 of Table 3. The atom molar ratio of these petal-like phases is similar to the gyrolite, which can be inferred that it is also the gyrolite. At the same time, it can be seen from Figure $3 \mathrm{f}$ and region 12 of Table 3 that a small number of small flake-like gyrolite has not transformed into petal-like minerals. Combined with the results of XRD analysis, it can be speculated that when the synthesis temperature rises to $210^{\circ} \mathrm{C}$, the mesh-like crystalline $\mathrm{C}-\mathrm{S}-\mathrm{H}$ reacts with $\mathrm{Ca}(\mathrm{OH})_{2}$ and $\left(\mathrm{SiO}_{4}\right)$ of $\mathrm{Q}^{0}$ to form large flake-like gyrolite. Furthermore, with the increase of synthesis temperature, more flake-like gyrolite phase is generated. So, the crystal micromorphology evolves from large flake-like to small flake-like and finally to petal-like.

When the synthesis temperature increases to $240{ }^{\circ} \mathrm{C}$ and $250{ }^{\circ} \mathrm{C}$, it is found from Figure $3 \mathrm{G}, \mathrm{H}$ that the micromorphology of synthesis products is square flake-like, and these square flake-like phases are stacked together. EDS analysis results are shown in region 13 and region 15 of Table 3 . The atom molar ratio of square flake phase is similar 
to calcium silicate hydroxide hydrate, which can be inferred as calcium silicate hydroxide hydrate. Combined with XRD analysis results, it can be speculated that when the synthesis temperature rises to $240{ }^{\circ} \mathrm{C}$, the square flake-like calcium silicate hydroxide hydrate is generated through reaction of flake-like gyrolite and $\mathrm{Ca}(\mathrm{OH})_{2}$. Therefore, crystal micromorphology evolves from petal-like to square flake-like at $230{ }^{\circ} \mathrm{C}$. In addition, it is found from Figure $3 \mathrm{~g}$, h that there is a small amount of strip-like minerals and EDS analysis results show these strip-like minerals are tobermorite as shown in region 14 and region 16 of Table 3. Therefore, it will further confirm that tobermorite is gradually formed when sythesis temperature reaches more than $240{ }^{\circ} \mathrm{C}$.

When the synthesis temperature continues to rise to $260^{\circ} \mathrm{C}$, it is found from Figure 3I,i that the micromorphology of the synthesis products is strip-like, and EDS analysis result is shown in the region 17 and region 18 of Table 3. Combined with XRD analysis results, it can be speculated that the atom molar ratio of strip-like phase is similar to tobermorite, which can be inferred as tobermorite phase. Therefore, it indicates, when the synthesis temperature rises to $260^{\circ} \mathrm{C}$, the square flake-like calcium silicate hydroxide hydrate reacted with $\mathrm{Ca}(\mathrm{OH})_{2}$ and $\left(\mathrm{SiO}_{4}\right)$ of $\mathrm{Q}^{0}$ to form strip-like tobermorite. Meanwhile, it can be seen from Figure 3I,i that almost all synthesis products of CSS and SF are strip-like tobermorite.

According to the above analysis, it can be seen that with increase of synthesis temperature, the main crystal evolution order of calcium silicate minerals synthesized by CSS and $\mathrm{SF}$ is cocoon-like $\mathrm{C}-\mathrm{S}-\mathrm{H}$, mesh-like $\mathrm{C}-\mathrm{S}-\mathrm{H}$, large flake-like gyrolite, small flake-like gyrolite, petal-like gyrolite, square flake-like galcium silicate hydroxide hydrate, and strip-like tobermorite.

\subsection{Micropore Parameters Evolution of Calcium Silicate Minerals with Increase of Hydrothermal Synthesis Temperature}

The micropore analyzer was used to analyze the micropore parameters of synthesis products of CSS and SF at different synthesis temperatures, and the results are shown in Figure 4. The APV, APD and SSA of synthesis products increase first and then decrease with increase of synthesis temperature.

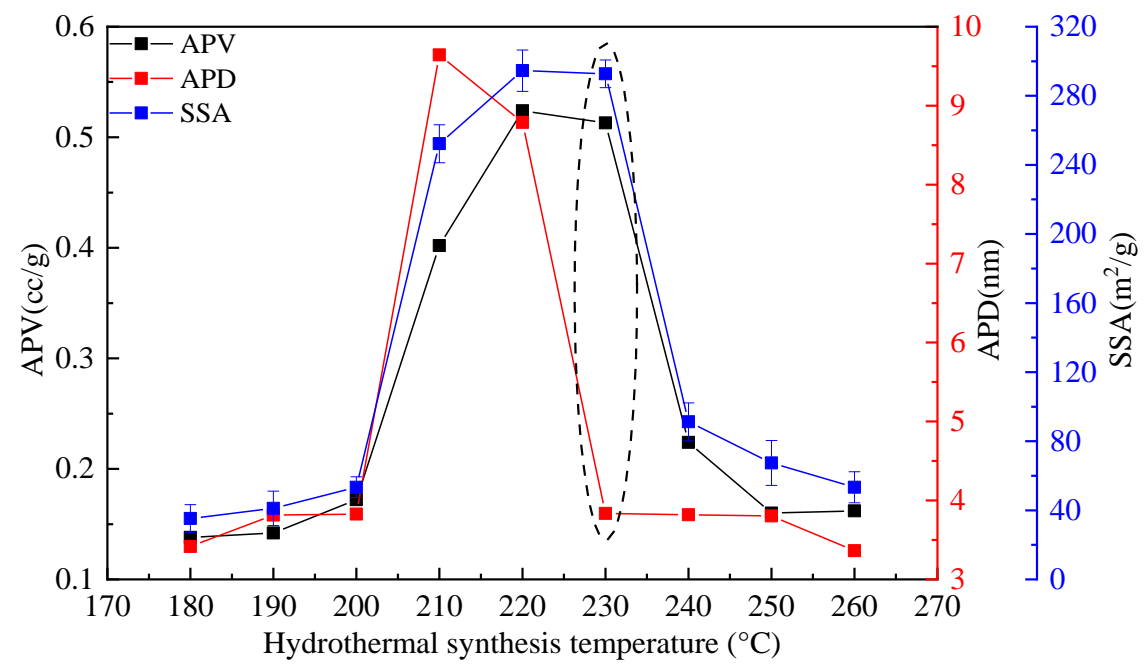

Figure 4. Change of micropore parameters for the synthesis product with increase of hydrothermal synthesis temperature.

According to Figure 4 and results of XRD and SEM, between synthesis temperature $180^{\circ} \mathrm{C}$ and $200^{\circ} \mathrm{C}$, the APV, APD and SSA of the synthesis products are relatively lower. At this synthesis temperature, the main phase is crystalline $\mathrm{C}-\mathrm{S}-\mathrm{H}$, with the increase of the synthesis temperature, the crystal evolves from cocoon-like crystalline $\mathrm{C}-\mathrm{S}-\mathrm{H}$ to mesh-like crystalline $\mathrm{C}-\mathrm{S}-\mathrm{H}$, and the grain size and pore size increase significantly. When the temperature rises to $210{ }^{\circ} \mathrm{C}$ and $230{ }^{\circ} \mathrm{C}$, the crystal of synthesis products evolves 
from crystalline $\mathrm{C}-\mathrm{S}-\mathrm{H}$ to flake-like gyrolite, and its SSA and APD increase significantly. Especially when the synthesis temperature is at $210{ }^{\circ} \mathrm{C}$, the APV, APD and SSA are very large due to the formation of large flake-like gyrolite. However, when the temperature is at $230{ }^{\circ} \mathrm{C}$, because the petal-like gyrolite is semi-closed pores, compared with the flake-like structure formed at $210^{\circ} \mathrm{C}$ and $220^{\circ} \mathrm{C}$, the APV and SSA of the synthesis products are relatively higher, but APD is relatively lower, as shown in Figure 4. In addition, there are also corresponding experimental results in the study of pore structure of calcium silicate hydrate $[26,27]$. When the temperature rises to $240{ }^{\circ} \mathrm{C}, 250{ }^{\circ} \mathrm{C}, 260{ }^{\circ} \mathrm{C}, \mathrm{APV}, \mathrm{APD}$ and SSA are lower, because crystal of main synthesis products is square flake-like and strip-like.

According to the above analysis results, with increase of synthesis temperature, the APV, APD and SSA of the synthesis products synthesized by CSS and SF show a change trend of first increase and then decrease. The average pore volume, average pore diameter and specific surface area are closely related to the crystal of main synthesis products. The APV, APD and SSA are smaller, when main synthesis products are cocoon-like and meshlike crystalline $\mathrm{C}-\mathrm{S}-\mathrm{H}$, square flake-like calcium silicate hydroxide hydrate and strip-like tobermorite. While the APV, APD and SSA are larger, when main synthesis products are flake-like gyrolite. However, because the petal-like gyrolite is semi-closed pores, it's the APV and SSA are relatively higher, but the APD is relatively lower.

\section{Conclusions}

In the paper, the dynamic hydrothermal synthesis experiments of CSS and SF were conducted under different hydrothermal synthesis temperature, and the phase category, microstructure, micropore parameters of the synthesis products were analyzed through the different testing methods, such as XRD, SEM, EDS, the micropore analysis and so on. The main aim is to discuss the hydrothermal synthesis reaction mechanism of CSS and SF and clarify the effect of synthesis temperature on the crystal formation and evolution of calcium silicate minerals. The conclusions are shown as follows:

(1) The main reaction mechanism of hydrothermal synthesis is that $\beta$-dicalcium silicate contained in CSS, firstly hydrates to generate amorphous $\mathrm{C}-\mathrm{S}-\mathrm{H}$ and $\mathrm{Ca}(\mathrm{OH})_{2}$, and the environment of system is induced to strong alkaline. Therefore, the highly polymerized $\mathrm{Si}-\mathrm{O}$ bond of $\mathrm{SF}$ are broken under the polarization of $\mathrm{OH}^{-}$to form $\left(\mathrm{SiO}_{4}\right)$ of $\mathrm{Q}^{0}$. At condition of high temperature and high press, amorphous $\mathrm{C}-\mathrm{S}-\mathrm{H}, \mathrm{Ca}(\mathrm{OH})_{2}$ and $\left(\mathrm{SiO}_{4}\right)$ of $\mathrm{Q}^{0}$ react each other to gradually produce various of calcium silicate minerals with higher and higher $\mathrm{C} / \mathrm{S}$ molar ratio with increase of synthesis temperature.

(2) With the increase of synthesis temperature, crystal evolution order of calcium silicate mineral synthesized by CSS and SF is cocoon-like C-S-H, mesh-like $\mathrm{C}-\mathrm{S}-\mathrm{H}$, large flakelike gyrolite, small flake-like gyrolite, petal-like gyrolite, square flake-like calcium silicate hydroxide hydrate, and strip-like tobermorite.

(3) With the increase of synthesis temperature, the APV, APD and SSA of the synthesis products show a change trend of first increase and then decrease. The APV, APD and SSA are closely related to the main crystal of synthesis products. However, because petal-like gyrolite is semi-closed pores, it's APV and SSA are relatively higher, but it's APD is relatively lower.

Author Contributions: Conceptualization, Z.Y.; methodology, Z.Y. and D.Z.; software, Z.Y.; validation, Y.J., C.F. and D.K.; formal analysis, C.Y. and J.Z.; investigation, Z.Y.; resources, Z.Y.; data curation, Z.Y.; writing-original draft preparation, Z.Y.; writing-review and editing, Z.Y.; visualization, Z.Y.; project administration, Z.Y.; funding acquisition, Z.Y. All authors have read and agreed to the published version of the manuscript.

Funding: This research was funded by Nature Science Foundation of Inner Mongolia, grant number 2019MS05076, Inner Mongolia Autonomous Region Science and Technology Plan Foundation, grant number 2020GG0287 and 2020GG0257, Inner Mongolia University of Technology Foundation, grant number ZZ201911 and Inner Mongolia University of Technology Doctor Foundation, grant number BS201916. 


\section{Institutional Review Board Statement: Not applicable.}

Informed Consent Statement: Not applicable.

Data Availability Statement: The data presented in this study are available on request from the corresponding author. At the time the project was carried out, there was no obligation to make the data publicly available.

Acknowledgments: The authors would like to thank Datang Renewable Resources company and Inner Mongolia Erdos Ferrosilicon alloy company for providing raw materials of experiments.

Conflicts of Interest: The authors declare no conflict of interest.

\section{References}

1. Daming, Z.; Jiang, C. Effects of surface modification of $\beta-\mathrm{CaSiO}_{3}$ on electrospun poly (butylenesuccinate) $/ \beta-\mathrm{CaSiO} 3 \mathrm{composite}$ fibers. Mater. Chem. Phys. 2009, 118, 379-384.

2. Fang, D.; Huang, L.; Fang, Z.; Zhang, Q.; Shen, Q.; Li, Y.; Xu, X.; Ji, F. Evaluation of porous calcium silicate hydrate derived from carbide slag for removing phosphate from wastewater. Chem. Eng. J. 2018, 354, 1-11. [CrossRef]

3. Huiquan, L.; Junbo, H.; Chenye, W.; Bao, W.; Sun, Z. Removal of sodium $\left(\mathrm{Na}_{2} \mathrm{O}\right)$ from alumina extracted coal fly ash by a mild hydrothermal process. Hydrometallurgy 2015, 153, 1-5.

4. $\quad$ Paradiso, P.; Santos, R.L.; Horta, R.B.; Lopes, J.; Ferreira, P.; Colaço, R. Formation of nanocrystalline tobermorite in calcium silicate binders with low C/S ratio. Acta Mater. 2018, 152, 7-15. [CrossRef]

5. Hossain, S.K.S.; Roy, P.K. Development of sustainable calcium silicate board: Utilization of different solid wastes. Boletín Soc. Española Cerámica Vidr. 2019, 58, 274-284. [CrossRef]

6. Bu, J.; Gonzalez Teresa, R.; Brown, K.G. Adsorption mechanisms of cesium at calcium-silicate-hydrate surfaces using molecular dynamics simulations. J. Nucl. Mater. 2019, 515, 35-51. [CrossRef]

7. Liu, J.H.; Zhang, M.Y.; Lu, Z.Q. Study on application of new silicate fillers extracted from fly ash in paper making. Tianjin Pap. Mak. 2013, 4, 7-12.

8. Qingfu, L.; Shilong, Z.; Junming, S. Study on properties of styrene butadiene rubber filled by active calcium silicate. J. Hunan Univ. Sci. Technol. (Nat. Sci. Ed.) 2013, 28, 95-99.

9. Leite, F.H.G.; Almeida, T.F.; Faria, R.T., Jr.; Holanda, J.N.F. Synthesis and characterization of calcium silicate insulating material using avian eggshell waste. Ceram. Int. 2017, 43, 4674-4679. [CrossRef]

10. Richardson, I.G. Tobermorite/jennite and tobermorite/calcium hydroxide-based models for the structure of C-S-H: Applicability to hardened pastes of tricalcium silicate, $\beta$-dicalcium silicate, Portland cement, and blends of Portland cement with blast-furnace slag. Cem. Concr. Res. 2004, 34, 1733-1777. [CrossRef]

11. Ma, J.; Qin, G.; Zhang, Y. Heavy metal removal from aqueous solutions by calcium silicate powder from waste coal fly-ash. $J$. Clean. Prod. 2018, 182, 776-782. [CrossRef]

12. Liu, L.; Liu, S.; Peng, H. Surface charge of mesoporous calcium silicate and its adsorption characteristics for heavy metal ions. Solid State Sci. 2020, 99, 106072. [CrossRef]

13. Liu, Y.; Jia, H.; Zhang, G. Synthesis and humidity control performances of natural opoka based porous calcium silicate hydrate. Adv. Powder Technol. 2019, 30, 2733-2741. [CrossRef]

14. Lee, C.; Alvarez, P.J.J.; Kim, H. Phosphorous recovery from sewage sludge using calcium silicate hydrates. Chemosphere 2018, 193, 1087-1093. [CrossRef] [PubMed]

15. Van, N.D.; Imasawa, K.; Hama, Y. Influence of hydrothermal synthesis conditions and carbonation on physical properties of xonotlite-based lightweight material. Constr. Build. Mater. 2022, 321, 126328.

16. Shiyue, H.; Huiquan, L.; Shaopeng, L. Kinetics of desilication process of fly ash with high aluminum from Kinetics of desilication process of fly ash with high aluminum from. Chin. J. Nonferrous Met. 2014, 24, 1888-1894.

17. Yang, Z.; Kang, D.; Zhang, D.; Yan, C.; Zhang, J. Crystal transformation of calcium silicate minerals synthesized by calcium silicate slag and silica fume with increase of C/S molar ratio. J. Mater. Res. Technol. 2021, 15, 4185-4192.

18. Guan, W.; Ji, F.; Fang, Z.; Fang, D.; Cheng, Y.; Yan, P.; Chen, Q. Low hydrothermal temperature synthesis of porous calcium silicate hydrate with enhanced reactivity $\mathrm{SiO}_{2}$. Ceram. Int. 2014, 40, 4415-4420. [CrossRef]

19. Ogur, E.; Botti, R.; Bortolotti, M.; Colombo, P.; Vakifahmetoglu, C. Synthesis and additive manufacturing of calcium silicate hydrate scaffolds. Mater. Res. Technol. 2021, 11, 1142-1151. [CrossRef]

20. Pengxu, C.; Guanghui, L.; Jun, L. Alkali-reinforced hydrothermal synthesis of lathy tobermorite fibers using mixture of coal fly ash and lime. Constr. Build. Mater. 2020, 238, 117655.

21. Camerini, R.; Poggi, G.; Ridi, F.; Baglioni, P. The kinetic of calcium silicate formation from and calcium hydroxide nanoparticles. Colloid Interface Sci. 2022, 605, 33-43. [CrossRef] [PubMed]

22. Bensted, J.; Barnes, P. Structure and Performance of Cements, 2nd ed.; Applied Science Publishers: London, UK, 1983 ; pp. 67-69.

23. Drochytka, R.; Černý, V. Influence of fluidized bed combustion fly ash admixture on hydrothermal synthesis of tobermorite in the mixture with quartz sand, high temperature fly ash and lime. Constr. Build. Mater. 2020, 230, 117033. [CrossRef] 
24. Ríos, C.A.; Williams, C.D.; Fullen, M.A. Hydrothermal synthesis of hydrogarnet and tobermorite at $175{ }^{\circ} \mathrm{C}$ from kaolinite and metakaolinite in the $\mathrm{CaO}-\mathrm{Al}_{2} \mathrm{O}_{3}-\mathrm{SiO}_{2}-\mathrm{H}_{2} \mathrm{O}$ system: A comparative study. Appl. Clay Sci. 2009, 43, 228-237. [CrossRef]

25. Różycka, A.; Kotwica, $€$. Effect of alkali on the synthesis of single phase gyrolite in the system CaO-quartz- $\mathrm{H}_{2} \mathrm{O}$. Constr. Build. Mater. 2020, 239, 117799. [CrossRef]

26. Ganyu, Z.; Huiquan, L.; Shaopeng, L.; Xinjuan, X.; Xingrui, W. Crystallization of calcium silicate at elevated temperatures in highly alkaline system of $\mathrm{Na}_{2} \mathrm{O}-\mathrm{CaO}-\mathrm{SiO}_{2}-\mathrm{H}_{2} \mathrm{O}$. Mater. Prod. Eng. 2017, 25, 1539-1544.

27. Wenzel, O.; Schwotzer, M.; Müller, E.; Chakravadhanula, V.S.K.; Scherer, T.; Gerdes, A. Investigating the pore structure of the calcium silicate hydrate phase. Mater. Charact. 2017, 133, 133-137. [CrossRef] 